\title{
ppt Level Detection of Samarium(III) with a Coated Graphite Sensor Based on an Antibiotic
}

\author{
Mohammad Reza Ganjali, ${ }^{* \dagger}$ Morteza Rezapour,* Mohammad Reza PourJavid,* \\ and Soheila HAGHGOO**
}

* Departments of Chemistry, Tehran University, Tehran, Iran

**Center of Quality Control of Drugs, Tehran, Iran

\begin{abstract}
$N$-[2-[4-[[[(Cyclohexylamino)carbonyl]amino]sulfonyl]phenyl]ethyl]-5-methyl pyrazine carboxamide (glipizid) was explored as an electro-active material for preparing a polymeric membrane-based sensor selective to samarium ions. The membrane incorporated $30 \%$ poly(vinyl chloride) (PVC), 53\% benzyl acetate (BA), $11 \%$ glipizid and $6 \%$ sodium tetraphenyl borate. When coated on the surface of a graphite electrode, it exhibits Nernstian responses in the concentration range of $1.0 \times 10^{-5}$ to $1.0 \times 10^{-10} \mathrm{M}$, with a detection limit of $8.0 \times 10^{-11} \mathrm{M}$ samarium. The electrode shows high selectivity towards samarium over several cations (alkali, alkaline earth, transition and heavy metal ions), and specially lanthanide ions. The proposed sensor has a very short response time $(<15 \mathrm{~s})$, and can be used in a wide $\mathrm{pH}$ range for at least ten weeks. It was used as an indicator electrode in potentiometric titration of $\mathrm{Sm}$ (III) ions with an EDTA solution, and for determination of samarium in binary and ternary mixtures.
\end{abstract}

(Received March 24, 2003; Accepted March 22, 2004)

\section{Introduction}

Potentiometric detections based on ion-selective electrodes, a simple method, offer great advantages such as speed and ease of preparation and procedures, wide dynamic range, and low cost. These characteristics have inevitably led to sensors for several ionic species, and the list of available electrodes has grown substantially over the last few years. A very interesting development of potentiometric sensors is the construction of electrodes that respond selectively to lanthanide ions. In spite of examples of successful progress in the design of highly selective ionophores for various metal ions, there are only three reports on the development of selective and sensitive ionophores for samarium ions. ${ }^{1-3}$ All of these sensors have shown relatively high detection limits, and in some cases they showed low selectivities for samarium ions.

Potentiometric sensors prepared by coating polymeric films containing ion carriers on metallic or graphite conductors ${ }^{4}$ have been shown to be very effective for a wide variety of inorganic and organic cations and anions., ${ }^{5,6}$ Although the relevant processes that occur at membrane-solid contact interfaces are still not fully understood, electrodes of this type have become popular because they are very simple, durable, inexpensive, and capable of reliable response in a wide concentration range. These types of electrodes have a much higher mechanical resistance, and as such they have been used as potentiometric detectors in capillary electrophoresis. ${ }^{7,8}$

Recently, we reported some sensors for lanthanide ions, such as $\mathrm{Ce}^{3+}, \mathrm{Sm}^{3+}$ and $\mathrm{Yb}^{3+}{ }^{3,9-11}$ In this work, we introduce a novel coated graphite sensor based on an antibiotic as an excellent

$\doteqdot$ To whom correspondence should be addressed.

E-mail: Ganjali@khayam.ut.ac.ir neutral ion carrier for selective determination of ultra trace amounts of samarium ions in the presence of other cations, especially $\mathrm{Ce}^{3+}, \mathrm{La}^{3+}$, and $\mathrm{Gd}^{3+}$ ions.

\section{Experimental}

\section{Reagents}

Reagent grade dibutyl phthalate (DBP), benzyl acetate (BA), high relative molecular weight PVC, sodium tetraphenyl borate (NaSTB) and tetrahydrofurane (THF) were purchased from Aldrich and were used as received. Samarium chloride and nitrate salts of the cations used (all from Merck) were of the highest purity available and were used without any further purification except for vacuum drying over $\mathrm{P}_{2} \mathrm{O}_{5}$. Triply distilled deionized water was used throughout. Glipizid (Fig. 1) was a gift from the center of quality control of drugs (Tehran, Iran).

\section{Electrode preparation}

The general procedure to prepare the PVC membrane was to mix thoroughly $30 \mathrm{mg}$ of PVC, $53 \mathrm{mg}$ of plasticizer BA, $6 \mathrm{mg}$ of additive NaTPB and $11 \mathrm{mg}$ of glipizid in a glass dish of $2 \mathrm{~cm}$ diameter. The mixture was completely dissolved in $3 \mathrm{~mL}$ of THF. The resulting clear mixture was evaporated slowly until an oily concentrated mixture was obtained. In order to prepare the coated graphite membrane electrodes, we used spectroscopic grade graphite rods of $3 \mathrm{~mm}$ diameter and $15 \mathrm{~mm}$ long. A shielded copper wire was glued to one end of the graphite rod, and the electrode was sealed into the end of a PVC tube of about the same diameter by epoxy resin. The working surface of the electrode was polished with fine alumina slurries on a polishing cloth, sonicated in distilled water and dried in air. The polished graphite electrode was dipped into the membrane 


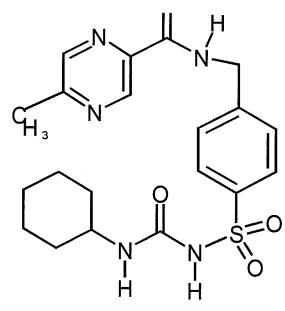

Fig. 1 Structure of glipizid.

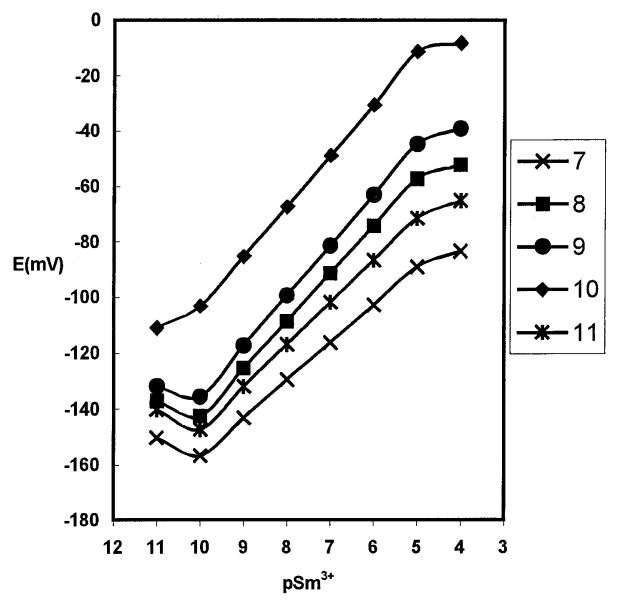

Fig. 2 Potential responses of Sm(III) ion-selective electrodes based on glipizid with different compositions: $\star$, No. 7 ; - - No. 8 ; No. $9 ;-$, No. $10 ; *$, No. 11.

solution mentioned above and the solvent was evaporated. A membrane was formed on the graphite surface. Then the electrode was allowed to rest overnight. ${ }^{10,12-14}$ The electrode was finally conditioned for $48 \mathrm{~h}$ by soaking in a $1.0 \times 10^{-3} \mathrm{M}$ solution of $\mathrm{SmCl}_{3}$.

\section{Emf measurements}

All emf measurements were carried out with the following assembly: graphite electrode/PVC membrane/test solution/ $\mathrm{Hg}_{2} \mathrm{Cl}_{2}$, $\mathrm{KCl}$ (satd.)

A Corning ion analyzer $250 \mathrm{pH} / \mathrm{mV}$ meter was used for potential measurements at $25.0 \pm 0.1^{\circ} \mathrm{C}$. The emf observations were made relative to a double-junction saturated calomel electrode (SCE, Philips) with the outer chamber filled with an ammonium nitrate solution. Activities were calculated according to the Debye-Hückle procedure. ${ }^{15}$

\section{Results and Discussion}

To the best of our knowledge, there is not any report on binding characteristics of glipizid. In the structure of glipizid exist six donor atoms (four $\mathrm{N}$, one $\mathrm{O}$ and one $\mathrm{S}$ in a semi cavity). All of these donor atoms can form a complex with cations and especially with transition metal ions. Thus, in order to obtain a clue about the stability and selectivity of the complexes of glipizid with a number of alkali, alkaline earth, transition heavy metal ions, we performed conductometric studies in acetonitrile solution at $25.0 \pm 0.1^{\circ} \mathrm{C}$. The results showed that, in all cases, the ligand to cation mole ratio is 1 , indicating the formation of stable 1:1 complexes between glipizid and the cations used.
Table 1 Optimization of membrane composition

\begin{tabular}{rcccccc}
\hline \multirow{2}{*}{ No. } & $\begin{array}{c}\text { PVC, } \\
\%\end{array}$ & $\begin{array}{c}\text { Plasticizer, } \\
\%\end{array}$ & $\begin{array}{c}\text { Ionophore, } \\
\%\end{array}$ & $\begin{array}{c}\text { Additive, } \\
\%\end{array}$ & Slope & L.R. \\
\hline 1 & 30 & DBP, 67 & 3 & - & 4.0 & $7 \times 10^{-9}-10^{-5}$ \\
2 & 30 & DBP, 65 & 5 & - & 4.5 & $4 \times 10^{-9}-10^{-5}$ \\
3 & 30 & DBP, 63 & 7 & - & 6.7 & $10^{-9}-10^{-5}$ \\
4 & 30 & DBP, 61 & 9 & - & 8.5 & $10^{-9}-10^{-5}$ \\
5 & 30 & DBP, 59 & 11 & - & 10.7 & $10^{-9}-10^{-5}$ \\
6 & 30 & DBP, 57 & 13 & - & 10.5 & $10^{-9}-10^{-5}$ \\
7 & 30 & BA, 59 & 11 & - & 13.5 & $10^{-9}-10^{-5}$ \\
8 & 30 & BA, 57 & 11 & 2 & 17.0 & $2 \times 10^{-10}-10^{-5}$ \\
9 & 30 & BA, 55 & 11 & 4 & 18.2 & $10^{-10}-10^{-5}$ \\
10 & 30 & BA, 53 & 11 & 6 & 19.3 & $10^{-10}-10^{-5}$ \\
11 & 30 & DBP, 53 & 11 & 6 & 15.1 & $10^{-10}-10^{-5}$ \\
\hline
\end{tabular}

The formation constant, $k_{\mathrm{f}}$, of the resulting 1:1 complexes were evaluated by computer fitting of the molar conductance-mole ratio data to appropriate equations; ${ }^{16,17}$ the stability values of the resulting complexes (except for $\mathrm{Sm}^{3+}$ with $\log k_{\mathrm{f}}>5.0$ ) were less than 2.5. The conductometric results obtained revealed that glipizid could be used as a highly selective ionophore for the preparation of $\mathrm{La}^{3+}$ ion-selective membrane electrode.

The glipizid-based membrane coated on the surface of graphite electrode generated stable potential responses in aqueous solutions containing $\mathrm{Sm}(\mathrm{III})$ ions after conditioning for $24 \mathrm{~h}$ in a $0.01 \mathrm{M}$ samarium solution. Table 1 gives the data obtained with membranes having various ratios of different constituents. The potential responses of all the membrane sensors were studied over a wide range of concentrations of samarium solution and the results are illustrated in Fig. 2. The electrode containing 11 wt $\%$ of glipizid exhibited linear responses in the range from $1.0 \times 10^{-10}$ to $1.0 \times 10^{-5} \mathrm{M}$, and can therefore be used in this concentration range, for the determination of samarium.

The potential responses of samarium and other cations to the membrane containing $11 \mathrm{wt} \%$ of glipizid in the range $1.0 \times 10^{-10}$ $-1.0 \times 10^{-5} \mathrm{M}$ are shown in Figs. 3(a) and 3(b). Except for the $\mathrm{Sm}$ (III) ion-selective electrode, for all other cations, the slope of the corresponding potential $v s$. pM plot is much lower than the expected Nernstian slopes of 59, 29.5 and $20 \mathrm{mV}$ per decade for the univalent, bivalent and trivalent cations, respectively.

As with many carrier-modified membrane electrodes, the total potentiometric response of the electrode towards samarium is dependent on the concentration of the glipizid and NaTPB incorporated within the membrane. As can be seen from Fig. 2 and Table 1, the increasing amounts of glipizid result in membranes that display larger slopes. Using $11 \mathrm{wt} \%$ of glipizid and $6 \%$ NaTPB in the membrane yielded an electrode with Nernstian slope towards samarium (membrane 10). As is obvious from Table 1, benzyl acetate is a more effective solvent mediator than dibutyl phthalate in preparing the $\mathrm{Sm}^{3+}$ ionselective electrode. It should be noted that the nature of the plasticizer influences both the dielectric constant of the membrane and the mobility values of the ionophore and its complex. A maximum slope of $19.3 \mathrm{mV}$ per decade of samarium concentration was observed for electrode (No. 10) with $30 \%$ PVC, $6 \%$ NaTPB, $11 \%$ glipizid and 53\% BA. The optimum response of the coated graphite electrode was tested after conditioning for different periods of time in a $0.001 \mathrm{M}$ samarium solution. The slope obtained using $48 \mathrm{~h}$ of conditioning was closer to the theoretical slope expected on the basis of the Nernst equation. Longer conditioning times produced no further improvements in the response. The 
(a)

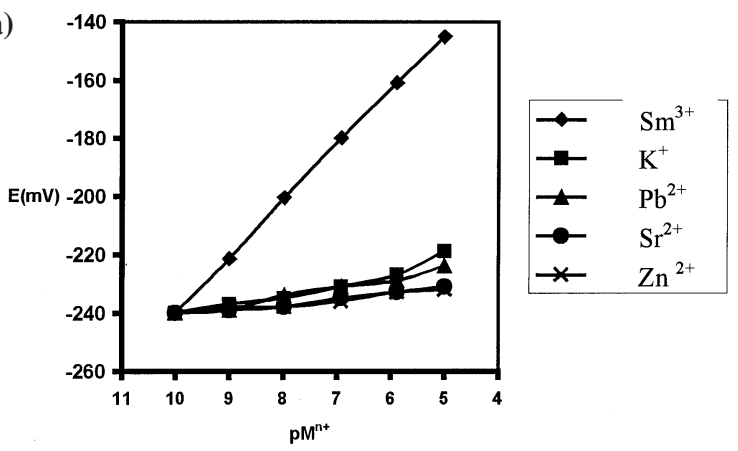

(b)

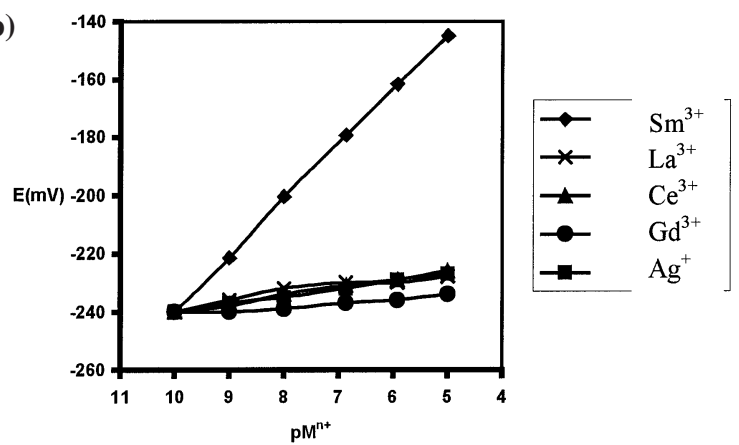

Fig. 3 Potential responses of different ion-selective electrodes based on glipizid.

optimum conditioning solution was determined to have a concentration of $0.001 \mathrm{M}$.

The average time required for the $\mathrm{Sm}^{3+}$ ion-selective electrode to reach a potential within $\pm 1 \mathrm{mV}$ of the final equilibrium value after successive immersions in a series of samarium ion solutions, each having a 10-fold difference in concentrations, was measured. The static response time thus obtained was $<15$ s over the entire concentration range. The sensing behavior of the membrane sensor remained unchanged when the potentials were recorded from low to high concentrations. The membrane electrodes prepared could be used for at least ten weeks without any measurable divergence.

Dynamic response time is an important factor for any ionselective electrode. In this study, the practical response time was recorded by changing the $\mathrm{Sm}^{3+}$ concentration in solution, over a concentration range of $1.0 \times 10^{-10}$ to $1.0 \times 10^{-5} \mathrm{M}$. The actual potential versus time traces are shown in Fig. 4. As can be seen, in the whole concentration range, the electrode reaches its equilibrium response in a very short time $(<15 \mathrm{~s})$. This is most probably, due to the fast exchange kinetics of complexation-decomplexation of $\mathrm{Sm}^{3+}$ ions with the ionophore at the test solution-membrane interface.

The potential response of the proposed samarium sensor (prepared under optimal membrane ingredients) indicates a rectilinear range from $1.0 \times 10^{-10}$ to $1.0 \times 10^{-5} \mathrm{M}$ (Fig. 5). The slope of the calibration curves was $19.3 \pm 0.4 \mathrm{mV} / \mathrm{dec}$ ade of samarium concentration. The limit of detection, as determined from the intersection of the two extrapolated segments of the calibration graph, was $8.0 \times 10^{-11} \mathrm{M}(12 \mathrm{ppt})$.

The influence of $\mathrm{pH}$ on the response of the coated graphite membrane electrode to a $1.0 \times 10^{-7} \mathrm{M} \mathrm{Sm}^{3+}$ solution was studied over the $\mathrm{pH}$ range of 1.0 to 11.5. The results are shown in Fig. 6. The membrane electrode can be suitably used in the $\mathrm{pH}$ range $3.0-10.5$. However, the changes observed below and above this $\mathrm{pH}$ range may be due to protonation of the glipizid

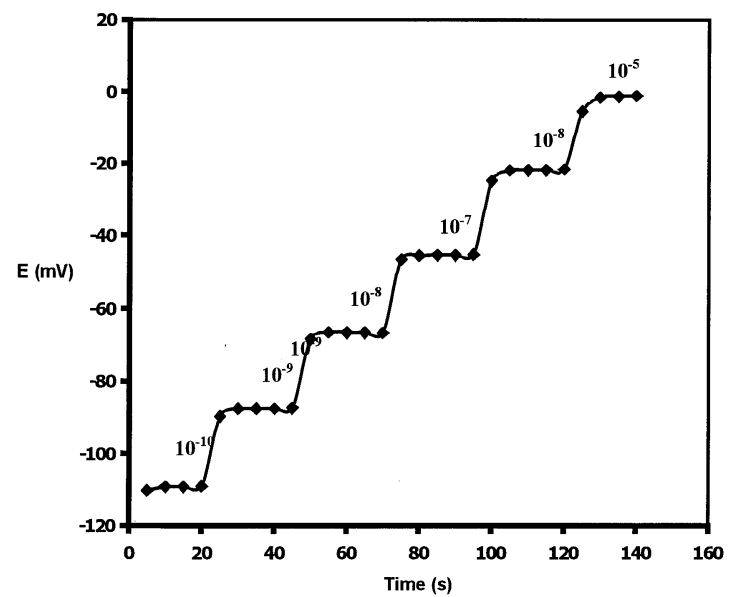

Fig. 4 Dynmic response time of Sm(III) sensor from low to high concentration $\left(10^{-10}-10^{-5}\right)$.

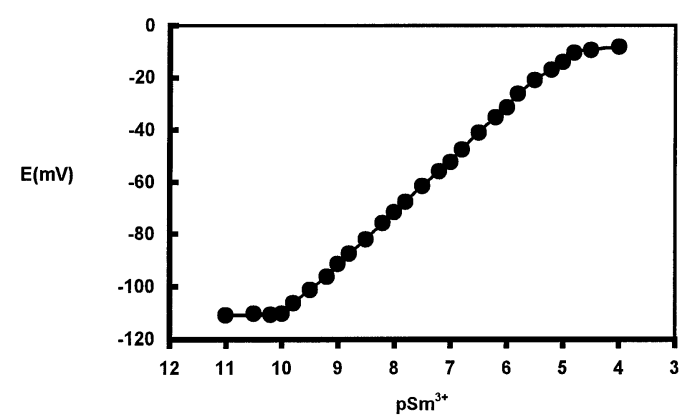

Fig. 5 Calibration graph of Sm(III) ion-selective electrodes based on glipizid with the best composition.

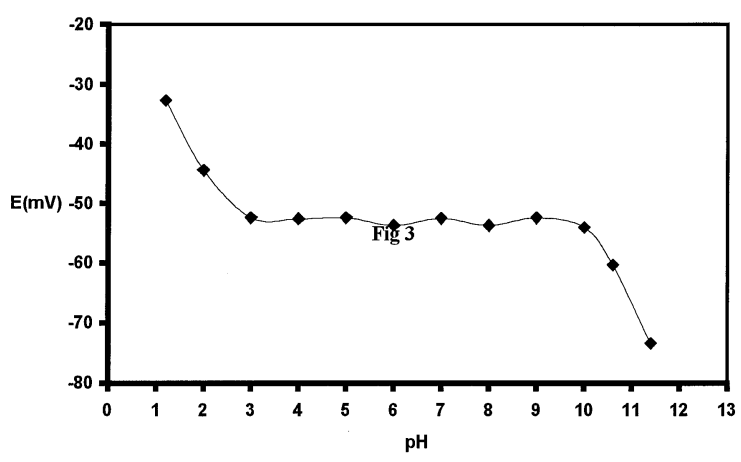

Fig. 6 Effect of $\mathrm{pH}$ of the test solution $\left(1.0 \times 10^{-7} \mathrm{M}\right.$ of $\left.\mathrm{Sm}(\mathrm{III})\right)$ on the potential response of the ion-selective electrode.

and formation of some hydroxy complex of samarium ions, respectively.

Selectivity behavior is obviously one of the most important characteristics of an ion-selective electrode, determining whether a reliable measurement in the target sample is possible. Potentiometric selectivity coefficient values for the present electrode were determined by the matched potential method ${ }^{18}$ by changing the concentration of the interfering ions $\left(1.0 \times 10^{-10}\right.$ $\left.1.0 \times 10^{-5} \mathrm{M}\right)$ in $1.0 \times 10^{-10} \mathrm{M} \mathrm{Sm}(\mathrm{III})$ solution. The selectivity testing of the electrodes with membranes (Nos. 7 - 11) was carried out, and results are summarized in Table 2 . 
Table 2 Comparison of selectivity coefficients of different electrodes

\begin{tabular}{llllll}
\hline Series 11 & Series 10 & Series 9 & Series 8 & Series 7 & Ion \\
\hline $5.2 \times 10^{-4}$ & $5.3 \times 10^{-5}$ & $1.3 \times 10^{-4}$ & $2.7 \times 10^{-4}$ & $1.2 \times 10^{-3}$ & $\mathrm{Li}^{+}$ \\
$5.5 \times 10^{-4}$ & $5.4 \times 10^{-5}$ & $1.5 \times 10^{-4}$ & $2.6 \times 10^{-4}$ & $1.6 \times 10^{-3}$ & $\mathrm{Na}^{+}$ \\
$7.7 \times 10^{-4}$ & $8.5 \times 10^{-5}$ & $2.5 \times 10^{-4}$ & $3.4 \times 10^{-4}$ & $2.5 \times 10^{-3}$ & $\mathrm{~K}^{+}$ \\
$6.3 \times 10^{-4}$ & $6.9 \times 10^{-5}$ & $2.2 \times 10^{-4}$ & $2.6 \times 10^{-4}$ & $2.1 \times 10^{-3}$ & $\mathrm{Ag}^{+}$ \\
$6.7 \times 10^{-4}$ & $7.3 \times 10^{-5}$ & $4.3 \times 10^{-4}$ & $4.5 \times 10^{-4}$ & $4.2 \times 10^{-3}$ & $\mathrm{Cu}^{2+}$ \\
$5.4 \times 10^{-4}$ & $6.5 \times 10^{-5}$ & $3.1 \times 10^{-4}$ & $3.6 \times 10^{-4}$ & $3.5 \times 10^{-3}$ & $\mathrm{Co}^{2+}$ \\
$4.1 \times 10^{-4}$ & $5.5 \times 10^{-5}$ & $2.3 \times 10^{-4}$ & $2.2 \times 10^{-4}$ & $2.4 \times 10^{-3}$ & $\mathrm{Ni}^{2+}$ \\
$3.2 \times 10^{-4}$ & $3.9 \times 10^{-5}$ & $0.8 \times 10^{-4}$ & $0.9 \times 10^{-4}$ & $0.9 \times 10^{-3}$ & $\mathrm{Mg}^{2+}$ \\
$5.2 \times 10^{-4}$ & $5.5 \times 10^{-5}$ & $2.6 \times 10^{-4}$ & $2.4 \times 10^{-4}$ & $2.5 \times 10^{-3}$ & $\mathrm{Ca}^{2+}$ \\
$4.3 \times 10^{-4}$ & $4.9 \times 10^{-5}$ & $1.5 \times 10^{-4}$ & $1.8 \times 10^{-4}$ & $1.7 \times 10^{-3}$ & $\mathrm{Sr}^{2+}$ \\
$2.9 \times 10^{-4}$ & $3.7 \times 10^{-5}$ & $0.7 \times 10^{-4}$ & $0.8 \times 10^{-4}$ & $0.7 \times 10^{-3}$ & $\mathrm{Ba}^{2+}$ \\
$7.6 \times 10^{-4}$ & $8.5 \times 10^{-5}$ & $2.9 \times 10^{-4}$ & $3.1 \times 10^{-4}$ & $2.9 \times 10^{-3}$ & $\mathrm{Cd}^{2+}$ \\
$7.0 \times 10^{-4}$ & $7.9 \times 10^{-5}$ & $2.2 \times 10^{-4}$ & $2.4 \times 10^{-4}$ & $2.2 \times 10^{-3}$ & $\mathrm{~Pb}^{2+}$ \\
$6.3 \times 10^{-4}$ & $6.8 \times 10^{-5}$ & $3.1 \times 10^{-4}$ & $2.5 \times 10^{-4}$ & $1.8 \times 10^{-3}$ & $\mathrm{La}^{3+}$ \\
$3.5 \times 10^{-4}$ & $3.7 \times 10^{-5}$ & $1.1 \times 10^{-4}$ & $1.2 \times 10^{-4}$ & $1.2 \times 10^{-3}$ & $\mathrm{Gd}^{3+}$ \\
$5.8 \times 10^{-4}$ & $6.3 \times 10^{-5}$ & $1.9 \times 10^{-4}$ & $2.6 \times 10^{-4}$ & $2.0 \times 10^{-3}$ & $\mathrm{Ce}^{3+}$ \\
\hline
\end{tabular}

Table 3 Comparison of different $\mathrm{Sm}^{3+}$ selective electrodes

\begin{tabular}{ccccc}
\hline & \multicolumn{4}{c}{ Selectivity coefficient } \\
\cline { 2 - 5 } $\mathrm{Mn}^{+}$ & $\begin{array}{c}\mathrm{Sm}^{3+} \\
(\text { This work })\end{array}$ & $\begin{array}{c}\mathrm{Sm}^{3+} \\
(\text { Ref. 3) }\end{array}$ & $\begin{array}{c}\mathrm{Sm}^{3+} \\
(\text { Ref. 2) }\end{array}$ & $\begin{array}{c}\mathrm{Sm}^{3+} \\
(\text { Ref. 1) }\end{array}$ \\
\hline Detection limit & $8.0 \times 10^{-11}$ & $6.0 \times 10^{-7}$ & $5.0 \times 10^{-8}$ & $5.0 \times 10^{-8}$ \\
\hline $\mathrm{Li}^{+}$ & $5.3 \times 10^{-5}$ & - & - & - \\
$\mathrm{Na}^{+}$ & $5.4 \times 10^{-5}$ & - & - & - \\
$\mathrm{K}^{+}$ & $8.5 \times 10^{-5}$ & $8.5 \times 10^{-4}$ & $1.3 \times 10^{-3}$ & $1.6 \times 10^{-3}$ \\
$\mathrm{Mg}^{2+}$ & $3.9 \times 10^{-5}$ & $2.5 \times 10^{-3}$ & $1.3 \times 10^{-3}$ & $2.5 \times 10^{-3}$ \\
$\mathrm{Ca}^{2+}$ & $5.5 \times 10^{-5}$ & $2.0 \times 10^{-3}$ & $5.0 \times 10^{-3}$ & $1.6 \times 10^{-2}$ \\
$\mathrm{Sr}^{2+}$ & $4.9 \times 10^{-5}$ & $2.3 \times 10^{-3}$ & - & - \\
$\mathrm{Ba}^{2+}$ & - & - & - & - \\
$\mathrm{Cu}^{2+}$ & $7.3 \times 10^{-5}$ & $1.5 \times 10^{-3}$ & $1.6 \times 10^{+1}$ & $1.6 \times 10^{+1}$ \\
$\mathrm{Co}^{2+}$ & $6.5 \times 10^{-5}$ & $8.5 \times 10^{-4}$ & - & - \\
$\mathrm{Ni}^{2+}$ & $5.5 \times 10^{-5}$ & $2.1 \times 10^{-3}$ & $6.3 \times 10^{-3}$ & $2.5 \times 10^{-3}$ \\
$\mathrm{Zn}^{2+}$ & - & - & $5.0 \times 10^{-3}$ & $2.0 \times 10^{-3}$ \\
$\mathrm{Cd}^{2+}$ & - & - & - & - \\
$\mathrm{Pb}^{2+}$ & $7.9 \times 10^{-5}$ & $9.2 \times 10^{-3}$ & $1.6 \times 10^{-1}$ & $1.6 \times 10^{-1}$ \\
$\mathrm{La}^{3+}$ & $6.8 \times 10^{-5}$ & $4.0 \times 10^{-3}$ & $8.9 \times 10^{-3}$ & $5.0 \times 10^{-3}$ \\
$\mathrm{Ce}^{3+}$ & $6.3 \times 10^{-5}$ & $8.0 \times 10^{-3}$ & $5.0 \times 10^{-2}$ & $2.5 \times 10^{-2}$ \\
$\mathrm{Gd}^{3+}$ & $3.7 \times 10^{-5}$ & $4.0 \times 10^{-3}$ & $3.9 \times 10^{-2}$ & $6.3 \times 10^{-2}$ \\
$\mathrm{Nb}^{3+}$ & - & - & - & - \\
\hline
\end{tabular}

Table 4 Recovery of Sm(III) ions

\begin{tabular}{ccc}
\hline $\mathrm{Sm}^{3+} / \mu \mathrm{g} \mathrm{ml}^{-1}$ & Added cation $/ \mu \mathrm{g} \mathrm{ml}^{-1}$ & Recovery, \% of $\mathrm{Sm}^{3+}$ \\
\hline 5.0 & - & $98.9 \pm 0.3$ \\
5.0 & $50 \mathrm{Na}^{+}$ & $99.7 \pm 0.3$ \\
5.0 & $500 \mathrm{Na}^{+}$ & $99.5 \pm 0.3$ \\
5.0 & $500 \mathrm{~K}^{+}$ & $99.4 \pm 0.6$ \\
5.0 & $500 \mathrm{Mg}^{2+}$ & $100.2 \pm 0.5$ \\
5.0 & $500 \mathrm{Fe}^{3+}$ & $100.1 \pm 0.6$ \\
5.0 & $500 \mathrm{Cu}^{2+}$ & $99.3 \pm 0.7$ \\
5.0 & $500 \mathrm{~Pb}^{2+}$ & $98.8 \pm 0.3$ \\
5.0 & $500 \mathrm{Ca}^{2+}$ & $99.1 \pm 0.7$ \\
\hline
\end{tabular}

The selectivity coefficient patterns clearly indicate that electrodes (Nos. 7 - 11) are selective to Sm(III) over several cations including alkali, alkaline earth, transition and heavy metal ions. The most important characteristic of the Sm(III)-

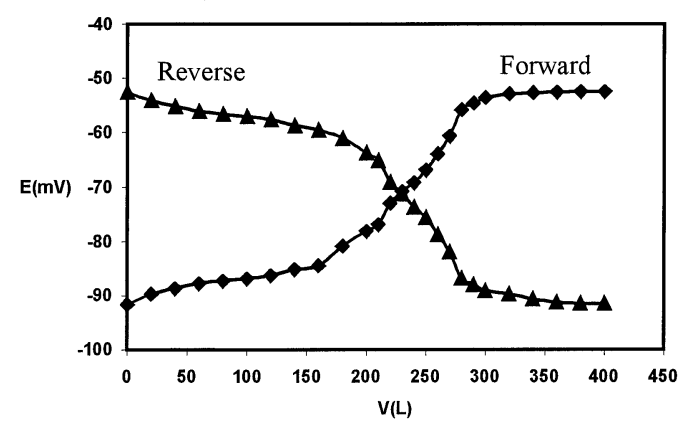

Fig. 7 Potentiometric titration curve of $25.0 \mathrm{~mL}$ of $1.0 \times 10^{-7} \mathrm{M}$ $\mathrm{Sm}$ (III) with $1.0 \times 10^{-5} \mathrm{M}$ of EDTA $(\mathrm{pH}=5.5)$, using the proposed membrane sensor as an indicator electrode.

electrode with membrane (No. 10) is its selectivity against other rare-earth ${ }^{1}$ cations. As is evident from Table 2, the selectivity coefficient values for $\mathrm{Ce}^{3+}, \mathrm{La}^{3+}$ and $\mathrm{Gd}^{3+}$ are in the range $3.7 \times$ $10^{-5}$ to $6.8 \times 10^{-5}$. These results clearly demonstrate that the glipizid can differentiate between the individual rare-earth ions, which was impossible with rare-earth electrodes based on a conventional solid-state sensor. ${ }^{19}$ A typical selectivity pattern presented by electrode (No. 10) towards several cations is as follows:

$$
\begin{aligned}
& \mathrm{Sm}^{3+}>>\mathrm{Cd}^{2+} \sim \mathrm{K}^{+}>\mathrm{Pb}^{2+}>\mathrm{Cu}^{2+}>\mathrm{Ag}^{+}>\mathrm{La}^{3+}>\mathrm{Co}^{2+}>\mathrm{Ce}^{3+} \\
& >\mathrm{Ca}^{2+} \sim \mathrm{Ni}^{2+}>\mathrm{Na}^{+}>\mathrm{Li}^{+}>\mathrm{Sr}^{2+}>\mathrm{Mg}^{2+}>\mathrm{Ba}^{2+} \sim \mathrm{Gd}^{3+}
\end{aligned}
$$

Table 3 compared the characteristics of the proposed coated graphite sensor with both the samarium coated carbon and membrane electrodes. As can be seen, not only the detection limit but also the selectivity coefficients of the proposed sensor are superior to those of all the previously reported samarium electrodes.

The Sm(III) sensor was also used for determination of $\mathrm{Sm}^{3+}$ in the presence of other cations (binary and ternary mixtures); the results are given in Table 4. As can be seen, the recovery of samarium ions in binary and ternary mixtures is very good.

The membrane sensor could successfully be used in the potentiometric titration of $\mathrm{Sm}$ (III) with EDTA. A $25.0 \mathrm{~mL}$ (1.0 $\left.\times 10^{-7} \mathrm{M}\right)$ solution of samarium was titrated with $1.0 \times 10^{-5} \mathrm{M}$ EDTA at $\mathrm{pH} 5.5$ and vice versa (Fig. 7). The $\mathrm{pH}$ of the solution was maintained by the addition of $\mathrm{HNO}_{3}$ and $\mathrm{NaOH}$. As is obvious from Fig. 7, the break point is relatively sharp and corresponds to the stoichiometry of the Sm-EDTA complex.

\section{References}

1. A. D. Chowdhury, T. Ogata, and S. Kamata, Anal. Chem., 1996, 68, 366.

2. T. Ogata, D. A. Chowdhury, S. Kamata, and Y. Ohashi, Chem. Lett., 1995, 2, 1041.

3. M. R. Ganjali, M. R. Pourjavid, M. Rezapour, and S. Haghgoo, Sens. Actuators, 2003, 89, 21.

4. Y. K. Lee, J. T. Park, C. K. Kim, and K. J. Whang, Anal. Chem., 1986, 58, 2101.

5. P. Schnierle, T. Kappes, and P. C. Hauser, Anal. Chem., 1998, 70, 3585.

6. P. B. Bühlmann, S. Yajima, K. Tohda, K. Umezawa, S. Nishizawa, and Y. Umezawa, Electroanalysis, 1995, 7, 811. 
7. Y. Yang, Y. Bi, M. Liu, J. Fu, and Z. Xi. Microchem. J., 1997, 55, 348.

8. B. L. D. Backer and L. J. Nagels, Anal. Chem., 1996, 68, 4441.

9. M. Shamsipur, M. Yousefi, and M. R. Ganjali, Anal. Chem., 2000, 72, 2391.

10. M. Shamsipur, M. Yousefi, M. Hosseini, and M. R. Ganjali, Anal. Lett. 2001, 34, 2249.

11. M. R. Ganjali, L. Naji, T. Poursaberi, M. Yousefi, M. Yeganeh, and M. Shamsipur, Anal. Chim. Acta, 2002, in press.

12. M. R. Ganjali, M. Hosseini, M. Salavati-Niasari, T. Poursaberi, M. Shamsipur, M. Javanbakht, and O. R. Hashemi, Electroanalysis, 2002, 14, 526.

13. M. R. Ganjali, T. Poursaberi, L. H. A. Babaei, S. Rouhani,
M. Yousefi, M. Kargar-Razi, A. Moghimi, H. Aghabozorg, and M. Shamsipur, Anal. Chim. Acta, 2001, 81, 440.

14. M. Shamsipur, S. Rouhani, T. Poursaberi, M. R. Ganjali, H. Sharghi, and K. Niknam, Electroanalysis, 2002, 11, 729.

15. S. Kamata, A. Bhale, and Y. Fukunaga, Anal. Chem., 1988, 60, 2464.

16. M. R. Ganjali, A. Rouhollahi, A. R. Mardan, and M. Shamsipur, J. Chem. Soc. Faraday Trans., 1998, 94, 1559.

17. M. Shamsipur and M. Hassani, Solution Chem., 1994, 23, 721.

18. Y. Umezawa, K. Umezawa, and H. Sato, Pure Appl. Chem., 1995, 67, 507.

19. Y. Takasaka and Y. Suzuki, Bull. Chem. Soc. Jpn., 1979, 52,3455 . 